Review Article

\title{
The State-of-the-Art of Knowledge-Intensive Agriculture: A Review on Applied Sensing Systems and Data Analytics
}

\author{
Barun Basnet $(\mathbb{D})$ and Junho Bang (iD \\ Department of IT Applied System Engineering, Chonbuk National University, Jeollabuk-do, Republic of Korea \\ Correspondence should be addressed to Junho Bang; jhbang@jbnu.ac.kr
}

Received 16 March 2018; Revised 7 July 2018; Accepted 26 July 2018; Published 19 September 2018

Academic Editor: Wesley Beccaro

Copyright ( 2018 Barun Basnet and Junho Bang. This is an open access article distributed under the Creative Commons Attribution License, which permits unrestricted use, distribution, and reproduction in any medium, provided the original work is properly cited.

\begin{abstract}
The application of sensors and information and communication technology (ICT) in agriculture has played a vital role in improving agricultural production and the value chain. Recently, the use of data analytics has shifted agriculture from inputintensive to knowledge-intensive as a large amount of agricultural data can be stored, shared, and analyzed to create information. In this paper, we have reviewed existing sensors and data analytics techniques used in different areas of agriculture. We have classified agriculture into five categories and reviewed the state-of-the-art technology in practice and ongoing research in each of these areas. Also, we have presented a case study of Korean scenario compared with other developed nations and addressed some of the issues associated with it. Finally, we have discussed current and future challenges and provided our views on how such issues can be addressed.
\end{abstract}

\section{Introduction}

The Food and Agriculture Organization of the UN (FAO) predicts that the global population will reach 9.2 billion by 2050 , and food production must increase by 70 percent to keep the pace [1]. The income distribution in the world is uneven and hugely divided. In one part of the world, prosperity exists, and there is always demand for high-quality food. While in another part of the world, hunger and war exist, and there is always demand for a large quantity of foods. With limited farming land and freshwater resources, this quality and quantity crisis in food can only be addressed by the application of ICT in agriculture. Both small- and large-scale farming can benefit from introducing ICT into the agriculture value chain, having their productivity increased, quality improved, services extended, and costs reduced. Furthermore, ICT facilitates information- and knowledge-based approach rather than only focusing on input-intensive agriculture. As a result, agriculture becomes more networked, and decision making and resource utilization could significantly be leveraged.

ICT in agriculture is interchangeably used as e-agriculture, smart agriculture, precision agriculture (PA), or IoT (internet of things) in agriculture depending upon the context. Modern agriculture is hugely automated, controlled, and constantly monitored. Sensors are the heart of ICT, and various sensing devices used for this purpose generate a large volume of data continuously. The application of data analytics helps in solidifying the research in agriculture. It provides insights into various issues in the agriculture like weather prediction, crop and livestock disease, irrigation management, and supply and demand of agriculture inputs and outputs and helps in solving those problems. It can also provide valuable information for optimum resource utilization and production boosting. Our work reviews research articles focused on agricultural data and provides insights on several agricultural issues.

A wide variety of review literature is available, covering the topic: sensors and ICT in agriculture. Ojha et al. [2] reviewed the use and the state-of-the-art of wireless sensor networks (WSNs) in agriculture. Their work covers applications, design, standards, and technologies of WSNs used in agriculture. Also, another article by same authors [3] reviewed and proposed a sensor-cloud framework for the efficient addressing of various agricultural problems and applications. Another review article included key vision control techniques and their potential applications in fruit or vegetable harvesting robots [4]. In particular, it looked 
at various vision schemes and recognition approaches for harvesting robots. Similarly, Zion [5] reviewed on the use of computer vision technologies in aquaculture. The review highlighted on the measurement, stock identification, and monitoring of different gender and species of aquatic animals. Other reviews included the keywords "ICT" and "agriculture" but were more focused on models and architectures in agriculture absorbing ICT [6, 7]. A recent article by Wolfert et al. [8] reviewed the state-ofthe-art of big data applications in smart farming and identifying socio-economic challenges associated with it. The article slightly touched the technological part but largely focused on socio-economic and governance issues for the design of suitable business models. Another recent article by Lan et al. [9] reviewed the state-of-the-art in precision agricultural aviation technology highlighting remote sensing, aerial spraying, and ground verification technologies. Likewise, a large number of research articles do exist, combining the use of artificial intelligence (AI), database, and advanced statistical tools in the agriculture [10-12]. However, a review article focused on sensors and data analytic techniques in the area of agriculture is still scarce in the literature.

This article aims to review the use of ICT especially sensors and data analytic techniques in the area of agriculture. Agriculture in this paper is used in a broader sense and covers research in crop cultivation, horticulture, animal husbandry, apiculture, and aquaculture. Our classification closely resembles the scientific classification of agriculture. By breaking agriculture into different subfields, and reviewing applied sensors and data analytics, we intend to complement existing reviews. The objective of this paper is to review research and development in the area of agriculture from the technological perspective highlighting its various subfields. Also, we intend to facilitate readers in comparing one subfield with the other subfields easily.

1.1. Associated Technical Terminologies. We briefly explain certain terms which frequently appears when we talk about ICT, sensors, and data analytics.

Sensors are electronic devices that measure a physical change in its environment and convert it into a suitable electrical form. Sensors like environmental sensors, airflow sensors, location sensors, electrochemical sensors, mechanical sensors, and optical sensors are used for acquiring various kinds of agricultural data. Smart sensors are capable of not only acquiring data but also store, process, and integrate such data. Sensor fusion is a combination of two or more sensor data to get additional insights or overcome the weakness of a single sensor. Wireless sensor networks (WSNs) are networks of such sensors connected wirelessly.

An embedded system is a microprocessor/controller embedded into an electro-mechanical system for performing a particular task. It is programmable and has limited memory and processing power. Most of the embedded systems are based on sensing systems consisting of sensors and actuators.

Internet of things (IoT) is a complex interconnected network of things that continuously exchange data. Here, "things" refer to any physical devices like sensors, cameras, wearables, vehicles, cell phones, and houses that are connected to the internet.

Cloud computing is an internet-based computing service where one can store, manipulate and retrieve data, and utilize resources from anywhere without actually owning the required hardware or software.

Data analytics techniques include analyzing and processing of acquired large datasets from the field and providing meaningful information so that any interested party may utilize them for their future work. Those large data sets are called big data, and the analytic technique is called data mining. A separate field of study called data science has emerged recently which combines computer algorithms and statistical methods for data analytics [13].

\section{Research Methodology and Motivation}

The primary purpose of this paper is to review the use of sensors and data analytics in different branches of agriculture. We frequently use ICT and sensors interchangeably in this paper as sensors are a key to the-state-of-the-art ICT, and sensor data are raw materials for any sort of data analytics. The terminology sensor used in this survey actually refers to sensing systems rather than the sensor devices itself. Likewise, agriculture is an enormous and vast area, and we do not attempt to review the use of ICT tools and techniques in every process, steps, fields, and subfields of agriculture. To narrow down, we have excluded prefield (genetics, seed/egg development) and postfield (distribution, processing, and consumer) and only reviewed the use of ICT tools and techniques for In-field applications, that is, planting/raising and harvesting. Also, the classification of the areas of agriculture in Section 3 is a general classification and might not exactly match with other sorts of classifications elsewhere. Figure 1 shows the evolution of different technologies used in the areas of the agriculture. However, we have excluded other (e.g., chemical, genetics, bioengineering) types of advancements made in the field of agriculture.

At large, only peer-reviewed research articles are provided as a reference for preparing this paper. However, reports and publications of various government and nongovernment organizations were also referred for understanding the perspectives outside academia in regard to challenges and future work direction. Also, our review does not contain research in agricultural machinery and robots but might cover certain underlying technologies if only they are relevant to sensors and data analytics tools.

\section{Sensors and Data Analytics in Agriculture}

3.1. Agronomy/Crop Farming. The general use of wireless sensor networks in crop monitoring and data acquisition can be found in various research and review articles [14-16]. Modern agronomical research and practice are becoming more and more data intensive. Data are continually collected, analyzed, and simulated to understand and predict crop growth and behavior under various circumstances.

Driemeier et al. [10] proposed a computational environment to support research in sugarcane precision agriculture. 


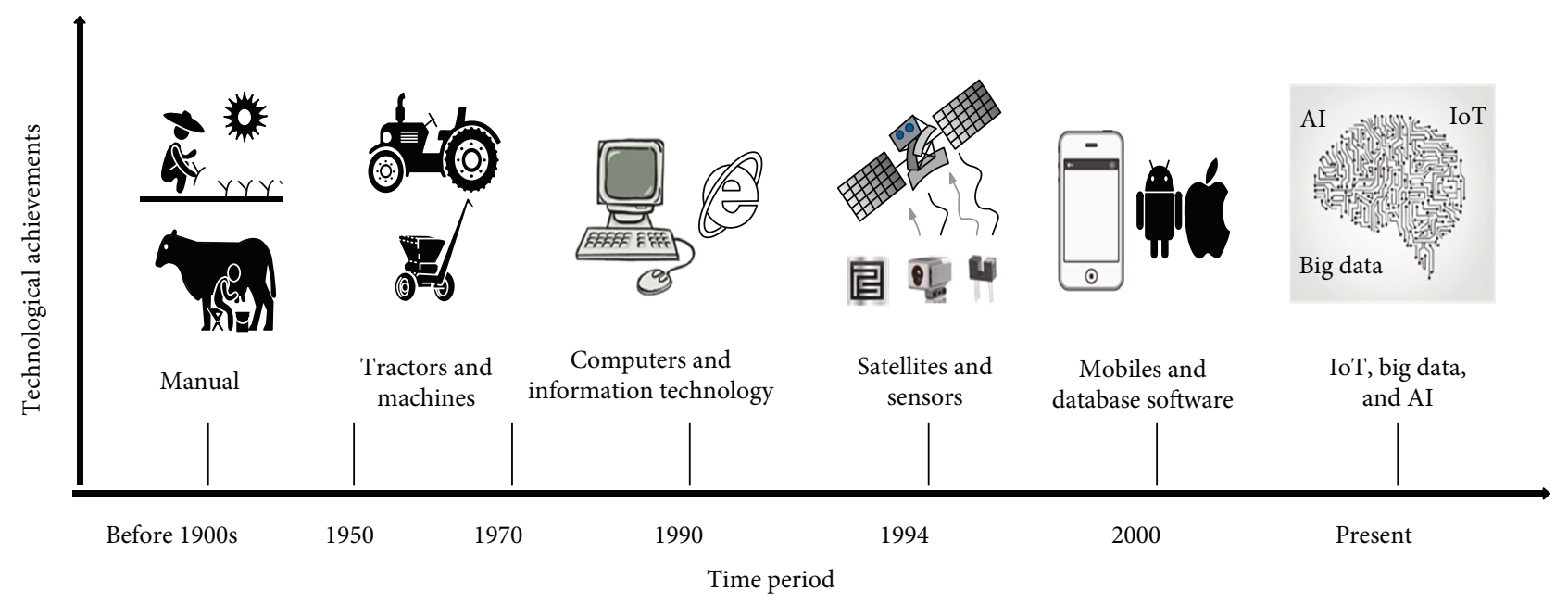

FIgURE 1: Evolution of different technologies used in the areas of the agriculture.

The work presented a data analysis workflow model for data acquisition, formatting, and verification. The model was employed to analyze three joint experiments comprised of soil attributes, sugarcane quality, and sugarcane yield. Yang et al. [11] reported the use of airborne multispectral and hyperspectral imagery and high-resolution satellite imagery for monitoring growth and estimating crop yield. They presented several application examples to demonstrate the advantages and limitations of different remote sensing and imagery analysis techniques. Similarly, Dong et al. [17] studied the feasibility of deriving spatially variable crop maximum light use efficiency $\left(L U E_{\max }\right)$ from satellite remote sensing data to improve crop biomass estimation. This study offered a new way to derive $L U E_{\max }$ for specific production efficiency models (PEM) and to improve the accuracy of biomass estimation using remote sensing. Equations (1), (2), and (3) represent an accuracy assessment model based on three statistical criteria.

$$
\begin{aligned}
\mathrm{RMSE} & =\sqrt{\left(\frac{1}{n}\right) \times \sum_{i=1}^{n}\left(E_{i}-M_{i}\right)^{2}}, \\
\mathrm{nRMSE} & =\frac{\mathrm{RMSE}}{\bar{M}} \times 100, \\
\operatorname{dindex} & =1-\frac{\sum_{i=1}^{n}\left(E_{i}-M_{i}\right)^{2}}{\sum_{i=1}^{n}\left(\left|E_{i}-\bar{M}\right|+\left|M_{i} \bar{M}\right|\right)^{2}} .
\end{aligned}
$$

Here, RMSE, nRMSE, and d-index represent the rootmean-square error, the normalized RMSE, and the index of agreement, respectively. A smaller value for both RMSE and nRMSE gives the higher estimation accuracy. The parameters inside the equations $n, M_{i}, E_{i}$, and $\bar{M}$ represent the number of observations, the measured value, the estimated value, and the mean of all measured values.

Similarly, Ge et al. [18] reported a study to characterize the temporal dynamics of maize plants' growth and water use through RGB (red, green, blue) images and automated pot weights. These methods proved to help in quantifying plant leaf water content. Figure 2 represents the hyperspectral image analysis to extract leaf pixels and the average leaf reflectance to predict plant leaf water content. Kristen et al. [19] reported sensor-based approaches to facilitate costeffective and site-specific management for soil health. The authors applied a sensor fusion approach (partial least square analysis) to estimate soil health indicators and soil management assessment framework (SMAF) scores using visible and near-infrared (VNIR) spectra in conjunction with electrical conductivity $\left(\mathrm{EC}_{\mathrm{a}}\right)$ sensor data. The fusion of $\mathrm{EC}_{\mathrm{a}}$ and CI data with VNIR improved estimation of the physical category and subsequently the overall SMAF soil health. However, chemical and fertility-related soil properties were not well estimated by this sensor fusion combination.

3.2. Horticulture/Plant Farming. Horticulture can sometimes be considered as a branch of agronomy concerned with the cultivation of plants, fruits, and vegetables rather than crops. The sensing technologies used in both areas are of similar nature. Various papers report design of greenhouse horticulture monitoring and control systems with WSN and commercially available embedded systems or IoT prototyping platforms [20-24].

Kim and Glenn [25] reported the development of a multimodal sensing system to identify the onset and severity of plant stress in young apple trees under different water treatments in a greenhouse. The data analysis result determined the spectral signature, and canopy temperature was highly correlated to plant water stress. Figure 3 represents thermal images of five different apple trees in the temperature range of $22.3^{\circ} \mathrm{C}$ to $40.7^{\circ} \mathrm{C}$. The rectangle in each image indicates the region of interest (ROI) for the calculation of canopy temperature. In a similar manner, Tian et al. [26] reported the design of a growth cabinet using an LED light source for hydroponics cultivation of rape plants. The work's focus was to design a light source made up of blue and red LEDs to predict and provide enough energy required by plants for photosynthesis at different growth stages. The designed system could also control microclimatic parameters like temperature, humidity, light intensity, and 


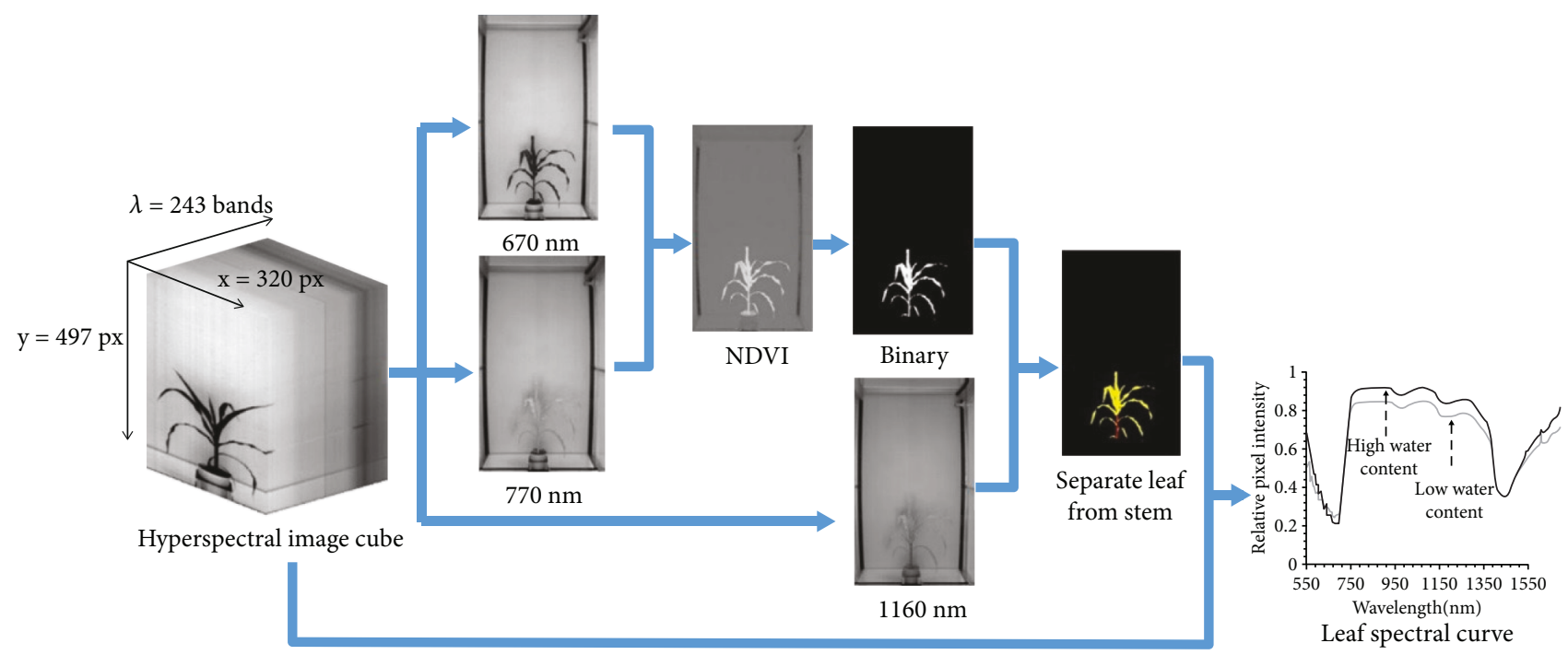

FIGURE 2: Hyperspectral image analysis to extract leaf pixels and the average leaf reflectance (pixel intensity) to predict plant leaf water content (Ge et al. [18]).

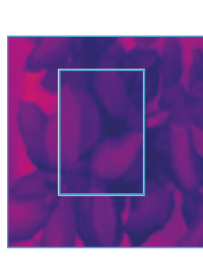

$100 \%$

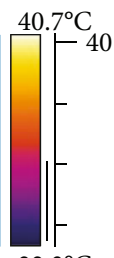

$22.3^{\circ} \mathrm{C}$

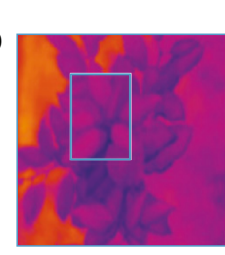

$75 \%$

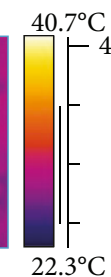

$22.3^{\circ} \mathrm{C}$

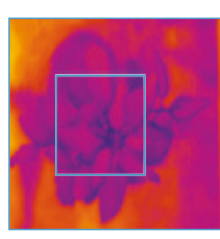

$65 \%$

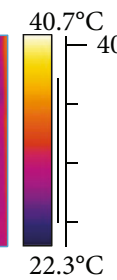

$22.3^{\circ} \mathrm{C}$

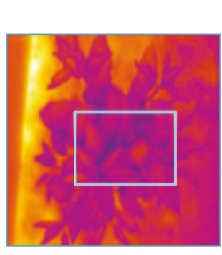

$55 \%$
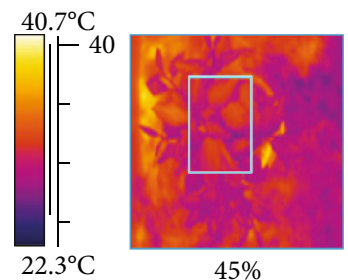

$45 \%$

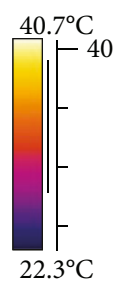

Figure 3: Thermal images of young apple trees in five different water treatments (Zhao et al. [4]).

$\mathrm{CO}_{2}$ concentration level inside the growth cabinet. Their experimental results demonstrated that the plants grew very well and even superior to the plants that grew in the natural environments in terms of height, growth time, and taste. Basnet et al. adopted [27] a moving average algorithm for smoothing out variations in sensed data for a greenhouse automation system. The algorithm could greatly help in stabilizing fluctuations caused by rapid change in the environment or imprecise sensors and thus bringing stable output.

$$
\begin{aligned}
& \operatorname{Avg}_{t 1}=\frac{1}{n-1}\left[x_{0}^{t 1}+x_{1}^{t 1}+x_{2}^{t 1}+\cdots+x_{n-1}^{t 1}\right], \\
& \operatorname{Avg}_{t 2}=\frac{1}{n}\left[x_{1}^{t 1}+x_{2}^{t 1}+x_{3}^{t 1}+\cdots+x_{n-1}^{t 2}\right] .
\end{aligned}
$$

Equation (4) represents the mathematical expression of the moving average algorithm presented in the work.

Rose et al. [28] researched the collection, classification, and quantization of phenotypic data of multiple vine rows using commercial multi-view-stereo software. Using a moving sensor platform (a track-driven vehicle, camera, GPS, and data acquisition hardware), morphological data of multiple vine rows were acquired. The authors claimed to complement existing $2 \mathrm{D}$ research with $3 \mathrm{D}$ solution-based image processing and demonstrated different data processing stages for predicting yields. Similarly, Zhao et al. [4] reviewed key techniques in vision-based control for harvesting fruits and vegetables. Their work presented an overview of various vision schemes (binocular, spectral, thermal, laser, etc.) and image processing algorithms (AdaBoost, Bayesian, fuzzy neural, etc.) for fruit recognition system.

Jesus et al. [29] proposed a field programmable gate array- (FPGA-) based wireless smart sensor for real-time photosynthesis monitoring system. A case study to monitor the photosynthetic response of chili pepper.

Capsicum annuum $L$. is made where the smart sensor acquires and fuses the primary sensor signals to measure temperature, relative humidity, solar radiation, $\mathrm{CO} 2$, air pressure, and air flow. The measurements are used to calculate net photosynthesis in real time and transmit the data via wireless communication to a sink node. In addition, the proposed smart sensor was equipped with signal processing ability, such as average decimation and Kalman filters, to the primary sensor readings so as to decrease the amount of noise in them as shown in Figure 4.

3.3. Animal Husbandry/Livestock Farming. Traditional animal husbandry requires the raising of a large flock of animals or cattle by experienced herdsmen. Modern animal husbandry called precision livestock farming (PLF) is about monitoring, tracking, and acquiring all sorts of data of livestock in real-time with the application of sensing systems and ICTs. These data are further processed and analyzed to 


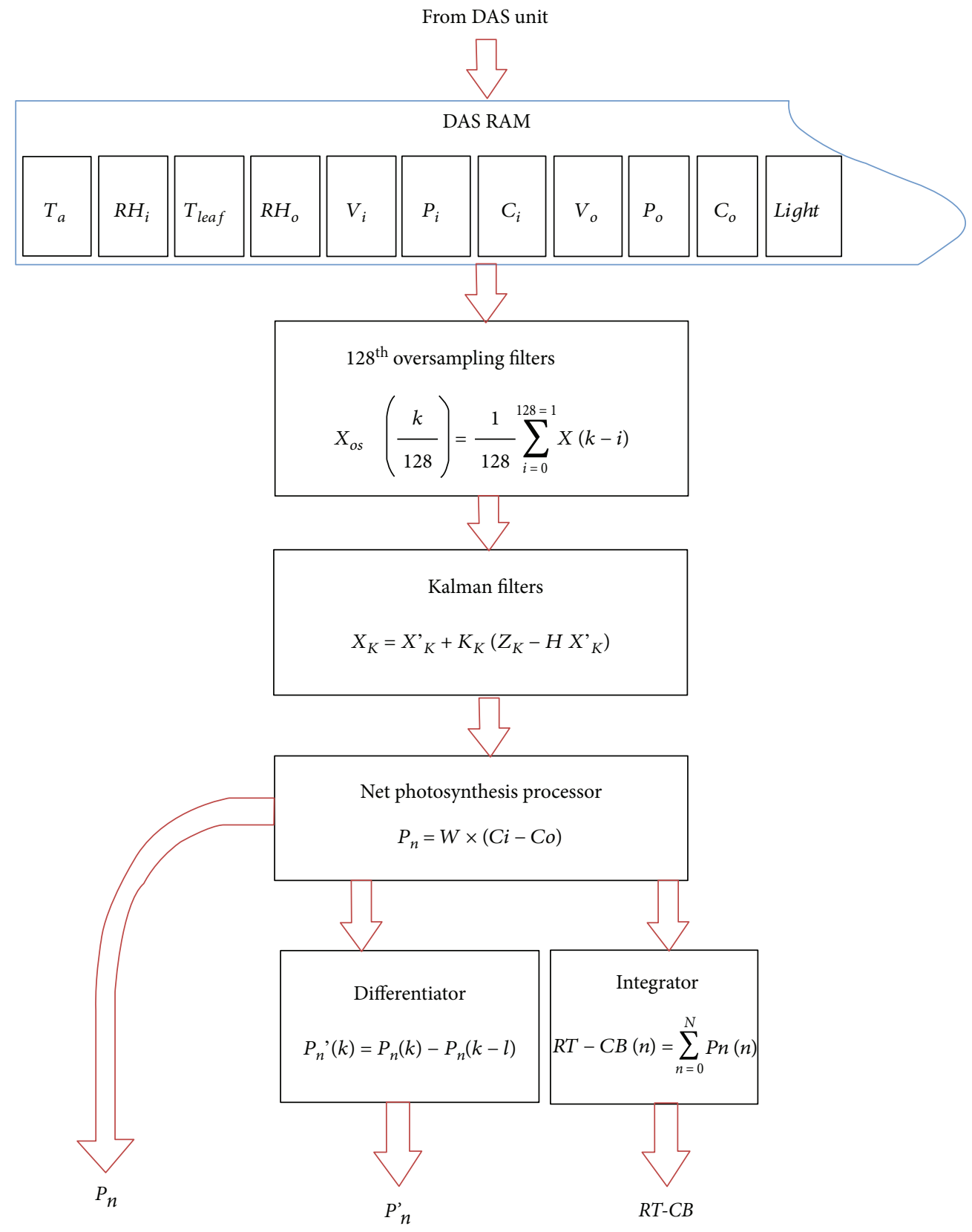

FIGURE 4: FPGA signal processing and smart processor unit (Jesus et al. [29]).

help in the decision-making process and provide a solution to various problems.

Aydin [30] reported a study to automatically assess the lameness of broiler by observing locomotion behaviors with the use of $3 \mathrm{D}$ vision camera and image process algorithm. The work is presented as a first attempt at assessing the lameness of broiler chickens with the use of $3 \mathrm{D}$ cameras having depth sensors as shown in Figure 5. Experiments were conducted to determine the number of lying events and latency to lie down of broiler chickens. The gait scores from 0 to 4 were chosen to rank lameness in the chicken. The proposed system had a high correlation between the output parameters against the manual labeling. Authors, therefore, asserted their work would be useful for developing an automatic animal monitoring and behavior analysis system to assess the health and welfare of broilers. Hongqian et al. [31] proposed a cloud-based data management system (CDMS) for automatic data collection for laying-hen farms. The CDMS facilitated asynchronous data transmission (Kafka-based), file distribution (Hadoop-based), information collection and management (MySQL-based) for the farms located in different areas. The system was set with 8 networking nodes and experimented at a commercial egg farm. The work expected to enhance the modern poultry in the efficient management of big data and record-keeping in real-time. Nkwari et al. [32] presented an article where a cow behavior is modeled using data collected from GPS sensors to get the expected position of it. The authors used the continuous-time 


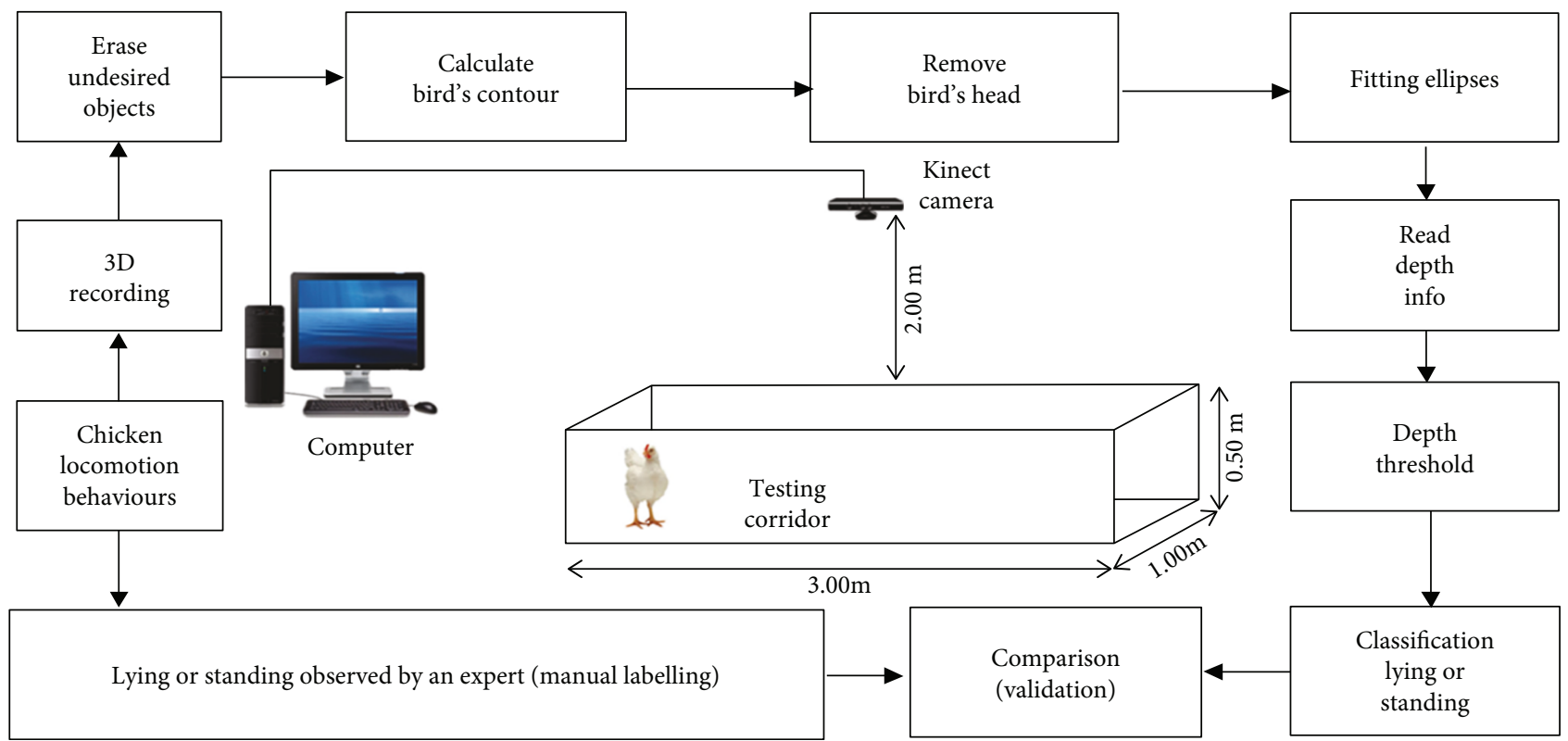

Figure 5: Flowchart of the image analysis and classification procedure using 3D vision camera (Aydin A 2017).

Markov process (CTMP) in order to model the random movement pattern (stochastic process) as shown in

$$
\begin{aligned}
P_{i j}^{(n)} & =P_{r}\left(X_{n}=j \mid X_{0}=i\right), \\
p_{b} & =p_{1}+p_{2}+p_{3}+p_{4}, \\
p_{1} & =P\left[a_{1} \leq r \leq b_{1}=\sum_{k} \frac{1}{n} .\right.
\end{aligned}
$$

Here, $P_{i j}$ is the total probability that the cow moves from the location $i$ to $j . P_{i j}^{(n)}$ represents the probability $P_{i j}$ after the cow has taken $n$ steps. $p_{1}, p_{2}, p_{3}$, and $p_{4}$ represent the probability the cow is in four different boundaries. $a_{1}$ and $b_{1}$ represent point limit of each boundary. By calculating which cow has a greater probability to get stolen, the work expects to help in preventing cattle rustling in farms.

Manteuffel et al. [33] presented a study which can help in preventing fatal piglet crushing events by mother sow. The work focuses on the extensive study of distress-specific vocalization to detect crushing events and thereby triggering for a mechanism to induce posture changes. Another study conducted by Feiyang et al. [34], a wireless network with the RFID tag collectors and weight sensors was employed to monitor chickens on a farm. The system detected sick chickens in the farm and classified them by studying their behaviors and parameters like the ability to snatch food, resting time, moving speed, and weight. The classification thus made and the extracted information is expected to facilitate precise husbandry and epidemic warning.

$$
\begin{aligned}
\operatorname{Stay}(i) & =\operatorname{Stay}_{\text {last }}(i)-\operatorname{Stay}_{\text {first }}(i), \\
D(i, j) & =\sqrt{\sum_{p=1}^{n}\left(x_{i p}-x_{j p}\right)^{2}, \quad i=\left(x_{i 1}, x_{i 2}, \ldots, x_{i p}\right), j=\left(x_{j 1}, x_{j 2}, \ldots, x_{j p}\right) .}
\end{aligned}
$$

Equation (6) represents the formula for chickens' resting time and the Euclidean distance formula applied in the $K$-means clustering method for the recognition of chickens' disease and quality, respectively. Here, Stay $(i)$ represents the total resting time of chicken $i$ from the beginning, that is, $\operatorname{Stay}_{\text {first }}(i)$ to last period of stay, that is, $\operatorname{Stay}_{\text {last }}$. In the same manner, $i=\left(x_{i 1}, x_{i 2}, \ldots, x_{i p}\right)$ and $j=\left(x_{j 1}, x_{j 2}, \ldots, x_{j p}\right)$ are two $p$-dimension objects with $D(i, j)$ Euclidean distance between them. The parameters $x_{i 1}, x_{i 2}, \ldots, x_{i p}$ are the chicken's ability to snatch food, weight, speed, and resting time of the chicken $i$. The same concept goes for another chicken j. Smaller Euclidean distance represents chickens of similar characteristics.

3.4. Apiculture/Beekeeping. Apiculture or beekeeping is a branch of agriculture where bee colonies are maintained in hives for harvesting honey. Various ICT technologies especially WSN were used previously to monitor the beehives and get various environmental data through sensors [33, 35-37]. Due to various environmental changes, their population is reported to be rapidly decreasing, and various interdisciplinary researches are going on to understand this phenomenon and provide possible solutions as well.

Murphy et al. [12] proposed a threshold-based algorithm and decision tree algorithms based on a biological study of bees to detect important hive changes and alert the beekeeper in a WSN for monitoring bee health. It classified hives as being in one of the ten possible states ranging from "normal" to "dead" which might or might not require an immediate response from the beekeeper. With the knowledge acquired, the beekeeper can automatically apply established beekeeping knowledge to the collected data, allowing early identification of poor health for improved colony health as well as analysis of the behavior. Figure 6 represents a decision tree algorithm to classify hive states of the bee colonies. Here, 


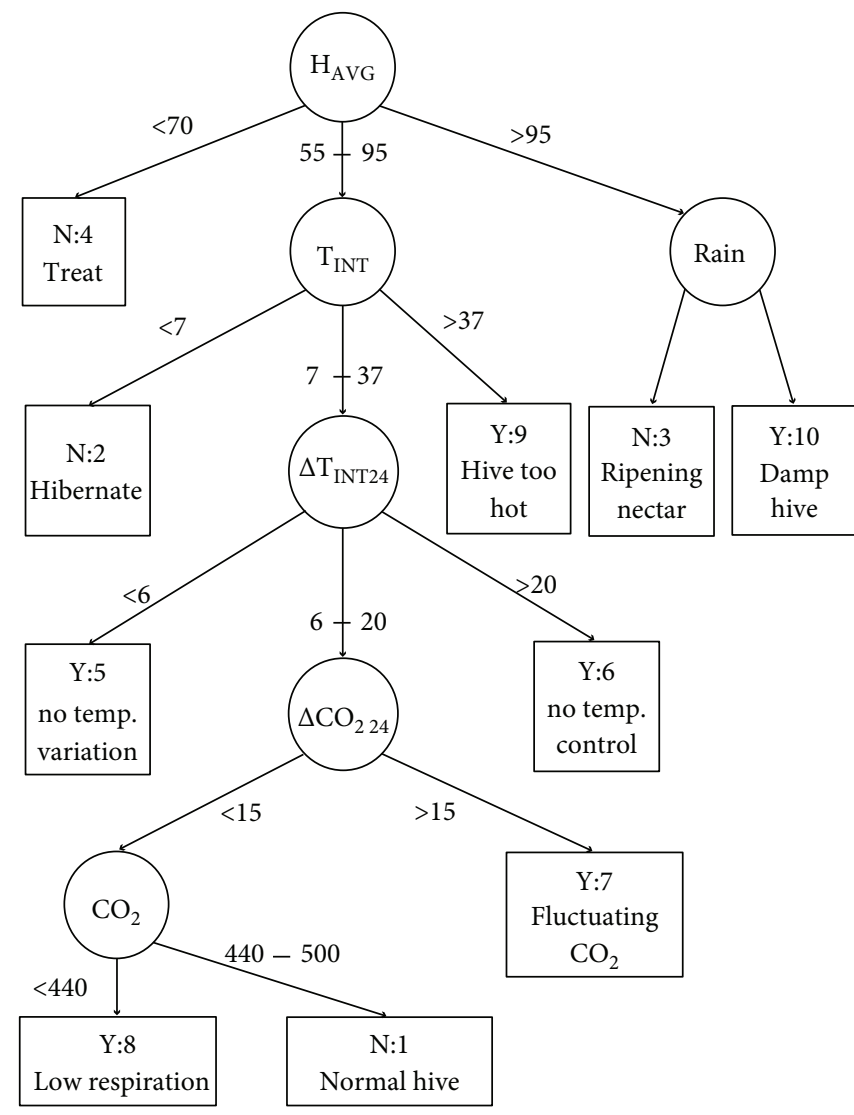

Figure 6: Decision tree induced from the training set for the hive classification (Murphy et al. [12]).

$\mathrm{H}_{\mathrm{AVG}}, \mathrm{T}_{\mathrm{INT}}, \Delta \mathrm{T}$, and $\Delta \mathrm{CO}_{2}$ represent average humidity, internal temperature, change in temperature, and change in $\mathrm{CO}_{2}$ concentration level, respectively.

Similarly, another work presented by Kviesis et al. [38], a hierarchical three-level model consisting of a wireless node, a local data server, and a cloud data server called WBee is designed for monitoring honey bee colonies. The main distinguishing work presented in the paper is the design of the system acquiring synchronized samples from all the hives and being able to save data at each level in case there is a communication failure.

3.5. Aquaculture/Fishkeeping. Aquaculture outputs have high demands in the global food market, and the application of ICT has helped to increase its quality and the production in recent years. Water quality is the most important parameter in aquaculture since health, appetite, growth, and other activities of aquatic animals depend on it. Various subparameters like dissolved oxygen (DO), $\mathrm{pH}$ level, temperature, salinity, turbidity, and ammonia nitrogen content affect the quality of water. Monitoring of such parameters and recirculating water periodically is essential in maintaining the quality of water.

Lebrero et al. [39] reported the design of multiparameters monitoring system where DO sensor, $\mathrm{pH}$ electrode, pt1000 temperature sensor, and NH3-N sensor were used to monitor aquaculture water quality. The system would trigger an aerator ON or OFF if the sensor would read below or above the threshold (4 to $5.5 \mathrm{mg} / \mathrm{L}$ ) of DO. Similar work by Hongpin et al. [40] reported on aquaculture monitoring system and control based on virtual instruments, additional features of power management, and networking solutions. The work has implemented sensor network nodes (dissolved oxygen sensor, temperature sensor, water level sensor, and $\mathrm{pH}$ sensor) in fish ponds for maximizing monitoring, control, and recording of the aquaculture system. With such benefits, the work reported on effectively reducing the probability of high risk of fish mortality, increase on economic benefit and consumer confidence, safety, and low energy consumption. The working concept of the designed system is presented in a flowchart as given in Figure 7.

Simbeye et al. [42] presented a multiple fish tracking systems in 3D space with structured-light (SL) sensor for acquisition of detailed information required for behavioral studies. Similarly, Saberioon and Cisar [41] used nearinfrared imaging technique to observe feeding process and behavior of fish. Their work $[41,42]$ can help to quantify such behavior of fish and can help in developing an automatic feeding system in the future. Figure 8 represents the work of infrared imaging technique to observe the feeding process of fish. Zion reviewed the use of computer vision technologies in aquaculture and reported the satisfactory level of works done in the area of edible or ornamental fish farms [5]. However, in the case of sea cage farms, the author points out the challenges in the application of the technology because of various parameters like deep water level, high 


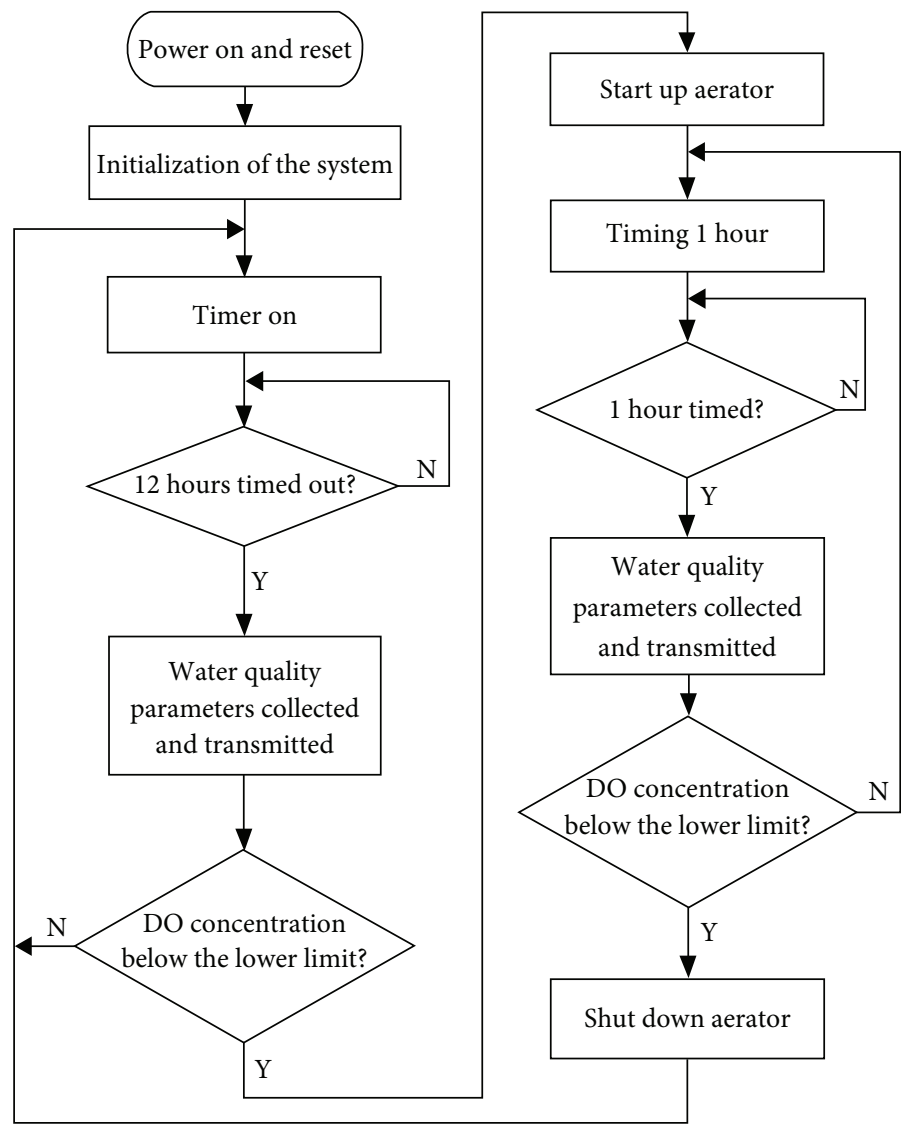

FIgURE 7: Flowchart of the remote monitoring system of aquaculture (Hongpin et al. [40]).

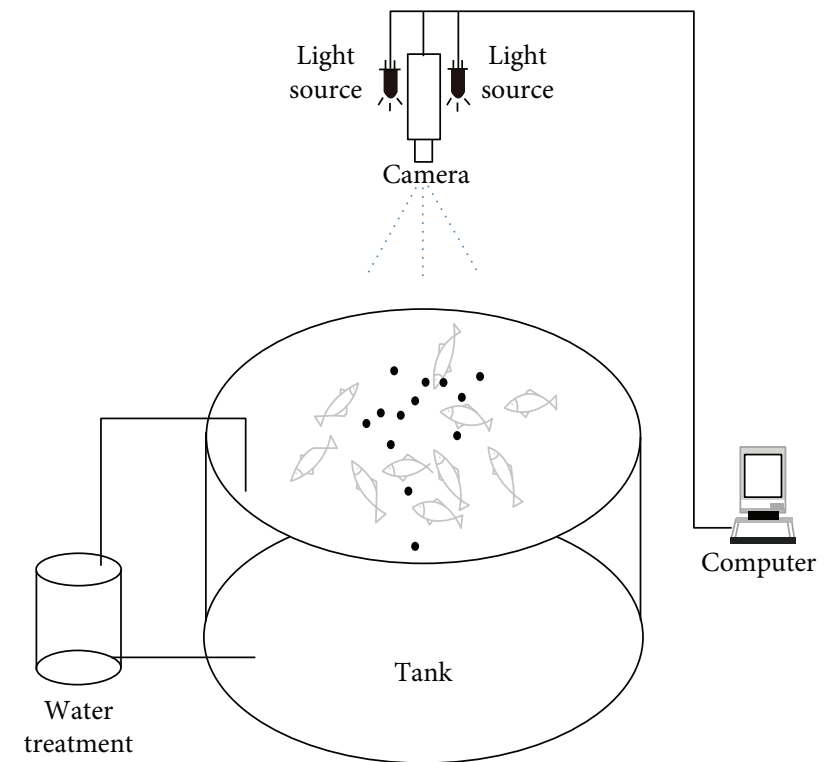

FIGURE 8: Infrared imaging technique to observe the feeding process (Saberioon and Cisar [41]).

turbidity, the presence of other aquatic animals, adjustment difficulty of feeding location, and lightening.

3.6. Chapter Conclusion. In this chapter, we reviewed various sensor-based technologies and data analytics techniques used in the field of agriculture. As mentioned in the previous chapters, agriculture is a very vast field and we do not attempt to review the application and development of different technologies in every process, steps, fields, and subfields of agriculture. We have only covered In-field applications.

There are other types of technological advancements made which has revolutionized the field of agriculture. Some of the noticeable things are advances in chemical fertilizers and pesticides, genetic engineering, soil and irrigation technology, agricultural tools and machinery, and production and distribution technology. However, review of such technologies is beyond the scope of this article. Table 1 shows the state-of-the-art use of different sensors and data analytics techniques presented in this work ([11-42]). Tables 2 and 3 show the state-of-the-art technology of different sensing system platforms and big data applications in smart farming and key issues, respectively.

\section{Korean Scenario}

South Korea is a highly industrialized country and hosts some of the world's huge leading tech-giants like Samsung, LG, and Hyundai. The Korean government has initiated steps in transferring the technology used in the industrial sector for the development of the agricultural sector as well. A report published by the Korean Rural Economic Institute emphasized the role of Korean agriculture in the nation's 
TABLE 1: Use of sensors and data analytic techniques in different areas of agriculture.

\begin{tabular}{|c|c|c|c|c|}
\hline Analytics and ICT & Sensors used & Purpose & Area & References \\
\hline Image processing & Satellite data Sensors & $\begin{array}{l}\text { Monitoring/estimating yield, } \\
\text { water content check, } \\
\text { feeding process observation }\end{array}$ & Agronomy, aquaculture & {$[4,11,17,41]$} \\
\hline Computer vision & 3D camera, depth sensors & $\begin{array}{c}\text { Lameness assessment, } \\
\text { harvesting fruit }\end{array}$ & Animal husbandry, horticulture & {$[27,28,34]$} \\
\hline Pattern recognition & $\begin{array}{l}\text { GPS/sensors, RFID/ } \\
\text { weight sensors, } \\
\text { structured light sensor }\end{array}$ & $\begin{array}{c}\text { Preventing cattle rustling } \\
\text { classifying/epidemic warning, } \\
\text { behavioral studies }\end{array}$ & Animal husbandry, apiculture & {$[31,32,42]$} \\
\hline WSN & Environmental sensors & Detect hive changes, monitoring & Apiculture, aquaculture & {$[35,38,40]$} \\
\hline Cloud computing & Smart devices, wireless nodes & $\begin{array}{l}\text { Remote access, } \\
\text { monitoring bee colonies }\end{array}$ & Animal husbandry, apiculture & {$[30,39]$} \\
\hline Others & Satellite LED and sensors & $\begin{array}{l}\text { Crop biomass estimation } \\
\text { hydroponics cultivation }\end{array}$ & Agronomy, horticulture & {$[18,26]$} \\
\hline
\end{tabular}

TABLE 2: The state-of-the-art of the sensing platforms in agriculture (Ojha et al. [2]).

\begin{tabular}{|c|c|c|c|c|c|c|}
\hline Feature & MICAZ & TelosB & IRIS & LOTUS & Imote2 & SunSPOT \\
\hline Processor & ATmega128 & IMSP430 & ATmega128 & $\begin{array}{l}\text { Cortex M3 } \\
\text { LPC } 17 \mathrm{xx}\end{array}$ & $\begin{array}{c}\text { Marvell/ } \\
\text { XScalePXA271 }\end{array}$ & ARM 920T \\
\hline Clock speed $(\mathrm{MHz})$ & 7.373 & 6.717 & 7.373 & $10-100$ & $13-416$ & 180 \\
\hline Bus width (bits) & 8 & 16 & 8 & 32 & 32 & 32 \\
\hline System memory $(\mathrm{kB})$ & 4 & 10 & 4 & 64 & 256 & 512 \\
\hline $\begin{array}{l}\text { Operating frequency } \\
\text { band }(\mathrm{MHz})\end{array}$ & 2400 & 2400 & 2400 & 2400 & 2400 & 2400 \\
\hline Transceiver chip & CC2420 & CC2420 & Atmel RF230 & Atmel RF231 & CC2420 & 802.15 .4 \\
\hline Number of channels & Programmable & Programmable & Programmable & - & In steps of $5 \mathrm{MHz}$ & - \\
\hline Data rate (kbps) & 250 & 250 & 250 & 250 & 250 & 250 \\
\hline I/O connectivity & $\begin{array}{l}\text { UART, I2C, } \\
\text { SPI, DIO }\end{array}$ & $\begin{array}{l}\text { UART, I2C, } \\
\text { SPI, DIO }\end{array}$ & $\begin{array}{l}\text { UART, I2C, } \\
\text { SPI, DIO }\end{array}$ & $\begin{array}{l}\text { 3xUART, SPI, I2C, } \\
\text { I2S, GPIO, ADC }\end{array}$ & $\begin{array}{l}\text { UART3x, SPI2x, I2C, } \\
\text { I2S, GPIO, DIO, JTAG }\end{array}$ & DIO, I2C, GPIO \\
\hline
\end{tabular}

TABLE 3: The state-of-the-art of big data applications in smart farming and key issues (Wolfert et al. [8]).

\begin{tabular}{|c|c|c|}
\hline Stages of the data chain & State of the art & Key issues \\
\hline Data capture & $\begin{array}{l}\text { Sensors, open data, unmanned aerial vehicles (UAV), } \\
\text { biometric sensing, genotype information, reciprocal data }\end{array}$ & Availability, quality, formats \\
\hline Data storage & $\begin{array}{c}\text { Cloud-based platform, Hadoop Distributed File } \\
\text { System (HDFS), hybrid storage systems, cloud-based } \\
\text { data warehouse }\end{array}$ & Quick and safe access to data \\
\hline Data transfer & Wireless, cloud-based platform, Linked Open Data & Safety, agreements on responsibilities and liabilities \\
\hline Data transformation & $\begin{array}{l}\text { Machine learning algorithms, normalization, } \\
\text { visualization and anonymization }\end{array}$ & $\begin{array}{l}\text { Heterogeneity of data sources, automation of } \\
\text { data cleansing and preparation }\end{array}$ \\
\hline Data analytics & $\begin{array}{l}\text { Yield models, planting instructions, benchmarking, } \\
\text { decision ontologies, cognitive computing }\end{array}$ & Semantic heterogeneity, real-time analytics, scalability \\
\hline Data marketing & Data visualization & Ownership, privacy, new business models \\
\hline
\end{tabular}

economic growth for the past 70 years [43]. It also reported the country's policy in investing in new technologies including ICT to cope with global warming, lack of resources, and changes in human consumption patterns. Similarly, the Electronics and Telecommunications Research Institute (ETRI) reported emerging ICT technologies to combine agricultural products at each stage in smart farms [44].
Koo et al. [45] reviewed Korean and international research trend related to ICT-based horticultural facilities. With keywords precision agriculture, smart farm, ICT, and IoT, the paper has thoroughly investigated technologies used in Korean agricultural scenario as shown in Table 4 . It has also provided various case studies on failures and given directions and solutions from several perspectives. It emphasizes 
TABLE 4: Core technologies for the realization of smart farm based on ICT (Koo et al. [45]).

\begin{tabular}{lr}
\hline Research objectives & Research content \\
\hline $\begin{array}{l}\text { Standardization and open } \\
\text { common platform }\end{array}$ & $\begin{array}{r}\text { Standardization of sensor technology and device. Building an open service platform. } \\
\text { User-oriented interface development. }\end{array}$ \\
$\begin{array}{l}\text { Sensor and instrumentation } \\
\text { technology }\end{array}$ & $\begin{array}{r}\text { Development of crop monitoring technology through image processing. Development of measuring } \\
\text { device for soil and crop biomaterial information. Developed a high-efficiency sensor and measuring } \\
\text { device. Real-time monitoring of electricity usage in the greenhouse complex. Monitoring and responding } \\
\text { to load on the surrounding ecosystem and environment. Establishment of a sensor network system and } \\
\text { improvement of battery or signal amplification technology of wireless measurement equipment. } \\
\text { Development of greenhouse complex environment control system algorithm. Developed smart grid } \\
\text { integrated greenhouse control algorithm linked with energy saving technology (renewable energy). } \\
\text { Development of differentiated ventilation fan and circulation fan control system. Development of } \\
\text { additional forced ventilation operation algorithm through ventilation analysis. }\end{array}$ \\
$\begin{array}{l}\text { Control and automation } \\
\text { performance evaluation }\end{array}$ & $\begin{array}{r}\text { ICT-based big data standardization, DB construction method development database analysis and } \\
\text { application software development. Smart farm model performance analysis program development. } \\
\text { Peb and mobile services }\end{array}$ \\
$\begin{array}{l}\text { Provides real-time management and production information through the web system. } \\
\text { Development of pest detection system and alarm system using image processing. }\end{array}$ \\
$\begin{array}{l}\text { Renewable energy and energy } \\
\text { load reduction technology }\end{array}$ & $\begin{array}{r}\text { Developing appropriate capacity of the unit farmhouse considering the economy. Energy saving } \\
\text { technology development for greenhouse structure and operation. Development of energy efficient } \\
\text { operation technology using renewable energy. }\end{array}$ \\
\hline
\end{tabular}

the development of an intelligent service system for management and control of all the process of agricultural production. Yeo [46] reported the development of a moving monitor and control system for crops in the greenhouse. The movable sensing units gather continuous data and the connection is made through the $\mathrm{Wi}-\mathrm{Fi}$ where the data are saved and processed on the server as shown in Figure 9. The movable sensing units consist of high-resolution IP camera, environmental sensors, and $\mathrm{Wi}-\mathrm{Fi}$ repeater and controlling units contain embedded PC, programmable logic controller (PLC), and BLDC motors. This work expects to provide a better solution in monitoring scheme and management of plants and crops in a greenhouse.

Another recent article published by Kim [47] researched on the estimation of the factors influencing the future prices of corn and wheat through Bayesian model averaging as shown in (7). With the application of probabilistic factors, the results of the study facilitate the improvement in the ability to forecast grain future prices.

$$
\operatorname{Pr}(A \mid B)=\frac{\operatorname{Pr}(B \mid A) \operatorname{Pr}(A)}{\operatorname{Pr}(B)}
$$

Here, $\operatorname{Pr}(A)$ and $\operatorname{Pr}(B)$ represents the probabilities of the occurrence of the events $\mathrm{A}$ and $\mathrm{B}$, respectively. Whereas, $\operatorname{Pr}(A \mid B)$ and $\operatorname{Pr}(B \mid A)$ represents a conditional probability of the likelihood of the occurrence of the event $A$ given $B$ is true and vice-versa.

\section{Challenges and Future Work Direction}

The use of sensors and data analytics gives a better hope for the agricultural sector, but challenges still remain. The factors associated with them which still need further attention are listed as Sections 5.1-5.6.
5.1. Sustainable Agriculture. While technological efforts are made in increasing the productivity of the agriculture, environmental and social factors are often not taken into account. In particular, developing countries prioritize on adopting technologies for fast development rather than a sustainable one [48]. Initiatives from the different sectors of society should be taken with a view to developing the sustainability of farming systems along with the adoption of the various technologies including sensors technology and ICT. Also, technology interventions should be designed to select appropriate and environment-friendly technologies for collecting, storing, recycling, and treating and disposing of e-waste [1].

5.2. Technological Constraint. Technology at hand determines the progress in each area of its application. The improvement in technology will add more precision, accuracy, speed, and reliability whereas reducing cost in the future. Standardization in technology is vital for the improvement in communication between farm equipment. Also, research and open source projects should be encouraged more to improve the overall quality of technological solutions [49].

5.3. End-User Oriented. Technological solutions should always be user-friendly. It should suit local contexts and needs. In the case of agricultural application, solution providers should take special care in making their products and solutions as easy, readable, and understandable as possible.

5.4. Big Data. Intelligent processing and analysis of a large amount of unstructured and heterogeneous data are required. Research show dimensional reduction in big data is necessary for core value extraction, and also the work is also equally challenging [50]. Open access to research and publication of these data are very important. But there exists ownership ambiguity of whom they belong to. Farmers? 


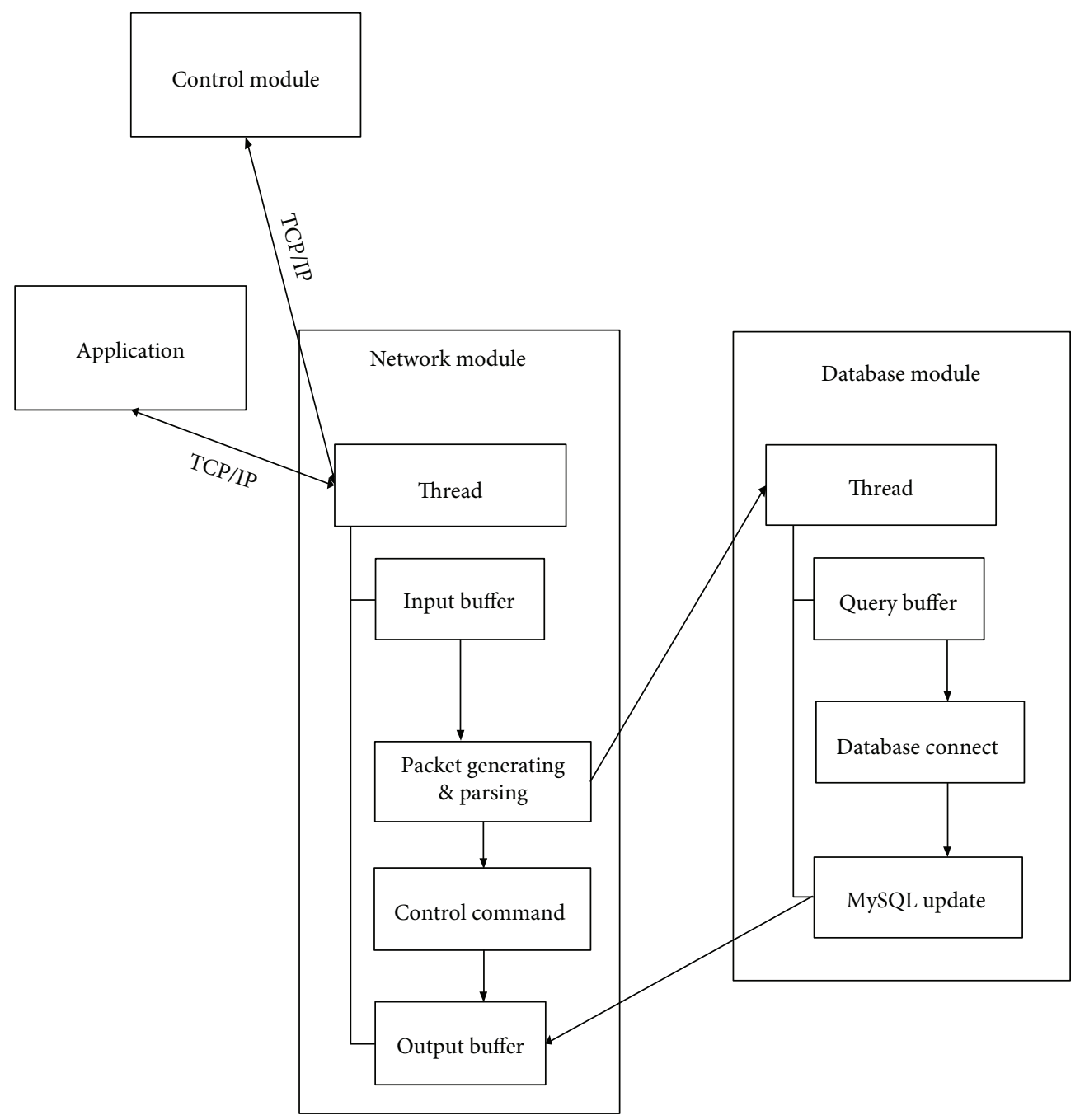

Figure 9: Server architecture proposed by Yeo et al. [46].

Companies? Or government? The problem should be addressed, but again if it is addressed too strictly, it can slow down innovations. Also, it is important to improve the understanding of big data usage. It is necessary to systematically promote the concept, its practical use, necessity, and value of use by expanding the education and sensitization of big data utilization [8].

5.5. Cost and Investment. Investing in the technology should not only make things easier to do but also help in increasing the return. Reduced cost increases the willingness to embrace the technology. Therefore, the cost of sensing systems and ICTs needs to be reduced, and their use needs to be financially sustainable. Farmers should be briefed about the economic consequences before and after the use of the technology [51].

5.6. Multidiscipline Collaboration. Not only through sensors technology and ICT but also many issues in the agriculture can be approached from various other disciplines. They can offer better solutions, enhance productivity, and provide other insights that agriculture scientists and other concerned parties might have overlooked. Collaboration and cooperation among experts from different fields will help in the betterment of the agricultural industry.

\section{Discussions and Conclusions}

In this paper, we presented a broad overview of the use of various sensors and data analytic techniques used in the area of agriculture. We divided the agriculture into five different subfields and reviewed on the state-of-the-art technology and research trends associated with each subfields. Sensor technologies especially IoTs and smart sensors have led to the exponential growth in sensor-based applications in agriculture. Our survey found the application of AI-based data analytics to be very active as many research was focused on these areas. As agriculture is becoming more data-intensive, these improvements in the technology have helped in the advancement of the area of agriculture. Many challenges still remain as we discussed in the "Challenge and Future work direction" section. However, at large, positive trends were identified, and we conclude that as sensors and data analytic techniques improve, it will bring more insights in solving a wide variety of agricultural issues. 


\section{Conflicts of Interest}

The authors declare that there are no conflicts of interest regarding the publication of this paper.

\section{Acknowledgments}

This work is a part of a research project (1801000664) supported by the National Research Foundation of Korea. The authors also would like to thank Dr. R. P. Tasho and the reviewers for their suggestions on improving the quality of this paper.

\section{References}

[1] N. Alexandratos and J. Bruinsma, "World agriculture towards 2010/2050," in The 2012 Revision, , pp. 1-3, Food and Agriculture Organization of the United Nations, 2012, Chapter 1.

[2] T. Ojha, S. Misra, and N. S. Raghuwanshi, "Wireless sensor networks for agriculture: the state-of-the-art in practice and future challenges," Computers and Electronics in Agriculture, vol. 118, pp. 66-84, 2015.

[3] T. Ojha, S. Misra, and N. S. Raghuwanshi, "Sensing-cloud: leveraging the benefits for agricultural applications," Computers and Electronics in Agriculture, vol. 135, pp. 96-107, 2017.

[4] Y. Zhao, L. Gong, Y. Huang, and C. Liu, "A review of key techniques of vision-based control for harvesting robot," Computers and Electronics in Agriculture, vol. 127, pp. 311-323, 2016.

[5] B. Zion, "The use of computer vision technologies in aquaculture - a review," Computers and Electronics in Agriculture, vol. 88, pp. 125-132, 2012.

[6] S. J. C. Janssen, C. H. Porter, A. D. Moore et al., "Towards a new generation of agricultural system data, models and knowledge products: Information and communication technology," Agricultural Systems, vol. 155, pp. 200-212, 2017.

[7] J. W. Kruize, J. Wolfert, H. Scholten, C. N. Verdouw, A. Kassahun, and A. J. M. Beulens, "A reference architecture for farm software ecosystems," Computers and Electronics in Agriculture, vol. 125, pp. 12-28, 2016.

[8] S. Wolfert, L. Ge, C. Verdouw, and M. J. Bogaardt, "Big data in smart farming- a review," Agricultural Systems, vol. 153, pp. 69-80, 2017.

[9] Y. Lan, S. Chen, and K. F. Bradley, "Current status and future trends of precision agricultural aviation technologies," International Journal of Agricultural and Biological Engineering, vol. 10, no. 3, pp. 1-17, 2017.

[10] C. Driemeier, L. Y. Ling, G. M. Sanches, A. O. Pontes, P. S. G. Magalhaes, and J. E. Ferreira, "A computational environment to support research in sugarcane agriculture," Computers and Electronics in Agriculture, vol. 130, pp. 13-19, 2016.

[11] C. Yang, J. H. Everitt, Q. du, B. Luo, and J. Chanussot, "Using high-resolution airborne and satellite imagery to assess crop growth and yield variability for precision agriculture," Proceedings of the IEEE, vol. 101, no. 3, pp. 582-592, 2013.

[12] F. Edwards-Murphy, M. Magno, P. M. Whelan, J. O'Halloran, and E. M. Popovici, "B+WSN: smart beehive with preliminary decision tree analysis for agriculture and honey bee health monitoring," Computers and Electronics in Agriculture, vol. 124, pp. 211-219, 2016.
[13] H. Wimmer and L. M. Powell, "A comparison of open source tools for data science," in Proceedings of the Conference on Information Systems Applied Research, vol. 8, pp. 4-12, Wilmington, NC, USA, 2015.

[14] Z. Liqiang, Y. Shouyi, L. Leibo, Z. Zhen, and W. Shaojun, "A crop monitoring system based on wireless sensor network," Procedia Environmental Sciences, vol. 11, pp. 558-565, 2011.

[15] A. Sivasankari and S. Gandhimathi, "Wireless sensor based crop monitoring system for agriculture using Wi-fi network dissertation," International Journal of Computer Science and Information Technology Research, vol. 2, pp. 293-303, 2014.

[16] K. Y. Bendigeri and J. D. Mallapur, "Advanced remote monitoring of a crop in agriculture using wireless sensor network topologies," International Journal of Electronics and Communication Engineering \& Technology, vol. 6, pp. 30-38, 2015.

[17] T. Dong, J. Liu, B. Qian et al., "Deriving maximum light use efficiency from crop growth model and satellite data to improve crop biomass estimation," IEEE Journal of Selected topics in Applied Earth observations and Remote sensing, vol. 10, no. 1, pp. 104-117, 2017.

[18] Y. Ge, G. Bai, V. Stoerger, and J. C. Schnable, "Temporal dynamics of maize plant growth, water use, and leaf water content using automated high throughput RGB and hyperspectral imaging," Computers and Electronics in Agriculture, vol. 127, pp. 625-632, 2016.

[19] K. S. Veum, K. A. Sudduth, R. J. Kremer, and N. R. Kitchen, "Sensor data fusion for soil health assessment," Geoderma, vol. 305, pp. 53-61, 2017.

[20] J. A. Enokela and T. O. Othoigbe, "An automated greenhouse control system using Arduino prototyping platform," Australian Journal of Engineering Research, vol. 1, no. 1, pp. 64-73, 2015.

[21] V. S. Jahnavi and S. F. Ahamed, "Smart wireless sensor network for automated greenhouse," IETE Journal of Research, vol. 61, no. 2, pp. 180-185, 2015.

[22] A. Salleh, M. K. Ismail, N. R. Mohamad, M. A. Aziz, M. A. Othman, and M. H. Misran, "Development of greenhouse monitoring uisng wireless sensor network through Zigbee technology," International Journal of Engineering Science Invention, vol. 2, pp. 2319-6734, 2013.

[23] R. Pahuja, H. K. Verma, and M. Uddin, "A wireless sensor network for greenhouse climate control," IEEE Pervasive Computing, vol. 12, no. 2, pp. 49-58, 2013.

[24] K. A. Eldhose, R. Antony, P. K. Mini, M. N. Krishnapriya, and M. S. Neenu, "Automated greenhouse monitoring system," International Journal of Engineering and Innovative Technology, vol. 3, pp. 164-166, 2014.

[25] J. Y. Kim and D. M. Glenn, "Measurement of photosynthetic response to plant water stress using a multi-modal sensing system," Transactions of the ASABE, vol. 58, no. 2, pp. 233-240, 2015.

[26] L. Tian, Q. Meng, L. Wang, and J. Dong, "A study on crop growth environment control system," International Journal of Control and Automation, vol. 7, no. 9, pp. 357-374, 2014.

[27] B. Basnet, I. Lee, M. Noh, H. Chun, A. Jaffari, and J. Bang, “An smart greenhouse automation system applying moving average algorithm," The Transactions of The Korean Institute of Electrical Engineers, vol. 65, no. 10, pp. 1755-1760, 2016.

[28] J. Rose, A. Kicherer, M. Wieland, L. Klingbeil, R. Töpfer, and H. Kuhlmann, "Towards automated large-scale 3D phenotyping of vineyards under field conditions," Sensors, vol. 16, no. 12 , pp. $2-15,2016$. 
[29] J. R. Millan-Almaraz, I. Torres-Pacheco, C. Duarte-Galvan et al., "FPGA-based wireless smart sensor for real-time photosynthesis monitoring," Computers and Electronics in Agriculture, vol. 95, pp. 58-69, 2013.

[30] A. Aydin, "Using 3D vision camera system to automatically assess the level of inactivity in broiler chickens," Computers and Electronics in Agriculture, vol. 135, pp. 4-10, 2017.

[31] C. Hongqian, H. Xin, T. Guanghui et al., "Cloud-based data management system for automatic real-time data acquisition from large-scale laying-hen farms," International Journal of Agricultural \& Biological Engineering, vol. 9, no. 4, pp. 106115, 2016.

[32] P. K. M. Nkwari, S. Rimer, and B. S. Paul, "Cattle monitoring system using wireless sensor network in order to prevent cattle rustling," in IST-Africa 2014 Conference Proceedings, Le Meridien Ile Maurice, Mauritius, May 2014.

[33] C. Manteuffel, E. Hartung, M. Schmidt, G. Hoffmann, and P. C. Schon, "Online detection and localisation of piglet crushing using vocalisation analysis and context data," Computers and Electronics in Agriculture, vol. 135, pp. 108-114, 2017.

[34] Z. Feiyang, H. Yueming, C. Liancheng, G. Lihong, D. Wenjie, and W. Lu, "Monitoring behavior of poultry based on RFID radio frequency network," International Journal of Agricultural and Biological Engineering, vol. 9, no. 6, pp. 139-147, 2016.

[35] J. F. Odoux, P. Aupinel, S. Gateff, F. Requier, M. Henry, and V. Bretagnolle, "ECOBEE: a tool for long-term honey bee colony monitoring at the landscape scale in West European intensive agroecosystems," Journal of Apicultural Research, vol. 53, no. 1, pp. 57-66, 2015.

[36] F. E. Murphy, E. Popovici, P. Whelan, and M. Mango, "Development of an heterogeneous wireless sensor network for instrumentation and analysis of beehives," in 2015 IEEE International Instrumentation and Measurement Technology Conference (I2MTC) Proceedings, Pisa, Italy, May 2015.

[37] D. W. Fitzgerald, F. E. Murphy, W. M. D. Wright, P. M. Whelan, and E. M. Popovici, "Design and development of a smart weighing scale for beehive monitoring," in 2015 26th Irish Signals and Systems Conference (ISSC), Carlow, Ireland, June 2015.

[38] A. Kviesis, A. Zacepins, M. Durgun, and S. Tekin, “Application of wireless sensor networks in precision apiculture," Engineering for Rural Development, vol. 20, pp. 440-445, 2015.

[39] S. Gil-Lebrero, F. J. Quiles-Latorre, M. Ortiz-López, V. Sánchez-Ruiz, V. Gámiz-López, and J. J. Luna-Rodríguez, "Honey bee colonies remote monitoring system," Sensors, vol. 17, p. 55, 2017.

[40] L. Hongpin, L. Guanglin, P. Weifeng, S. Jie, and B. Qiuwei, "Real-time remote monitoring system for aquaculture water quality," International Journal of Agricultural and Biological Engineering, vol. 8, no. 6, pp. 136-143, 2015.

[41] M. M. Saberioon and P. Cisar, "Automated multiple fish tracking in three-dimension using a structured light sensor," Computers and Electronics in Agriculture, vol. 121, pp. 215221, 2016.

[42] D. S. Simbeye, J. Zhao, and S. Yang, "Design and deployment of wireless sensor networks for aquaculture monitoring and control based on virtual instruments," Computers and Electronics in Agriculture, vol. 102, pp. 31-42, 2014.

[43] C. Zhou, B. Zhang, K. Lin et al., "Near-infrared imaging to quantify the feeding behavior of fish in aquaculture,"
Computers and Electronics in Agriculture, vol. 135, pp. 233241, 2017.

[44] Korea Rural Economic Institute, Agriculture in Korea, 2015.

[45] H. S. Koo, J. H. Min, and J. Y. Park, "2015 electronics and telecommunications trends," in Survey of ICT-Agriculture Convergence, ETRI, 2014.

[46] U.-h. Yeo, I.-b. Lee, K.-s. Kwon et al., "Analysis of research trend and core technologies based on ICT to materialize smart-farm," Protected Horticulture and Plant Factory, vol. 25, no. 1, pp. 30-41, 2016.

[47] H. J. Kim, "Development of a moving monitor system for growing crops and environmental information in green house," The Journal of Korea Institute of Information, Electronics, and Communication Technology, vol. 9, no. 3, pp. 285-290, 2016.

[48] B. R. Prasad and S. Agarwal, "Comparative study of big data computing and storage tools: a review," International Journal of Database Theory and Application, vol. 9, no. 1, pp. 45-66, 2016.

[49] S. G. Dutia, Agtech: Challenges and Opportunities for Sustainable Growth, Ewing Marion Kauffman Foundation, 2014.

[50] T. H. M. d. Oliveira, M. Painho, V. Santos, O. Sian, and A. Barriguinha, "Development of an agricultural management information system based on open-source solutions," Procedia Technology, vol. 16, pp. 342-354, 2014.

[51] K. Sabarina and N. Priya, "Lowering data dimensionality in big data for the benefit of precision agriculture," in International Conference on Intelligent Computing, Communication \& Convergence, Odisha, India, 2015. 


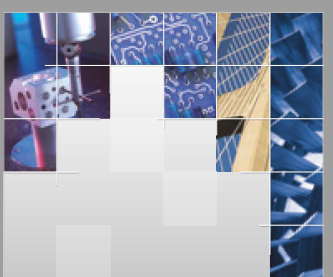

\section{Enfincering}
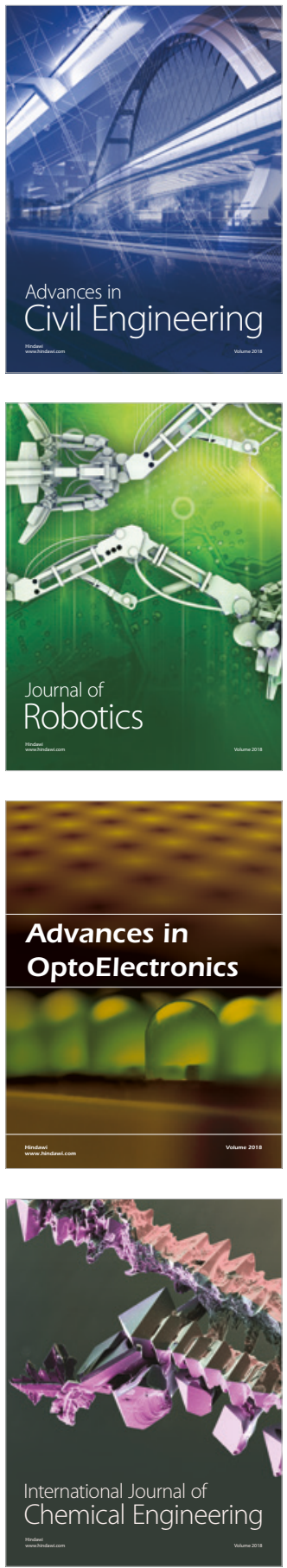

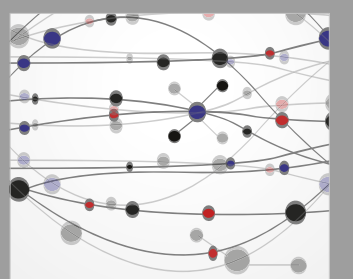

\section{Rotating \\ Machinery}

The Scientific World Journal

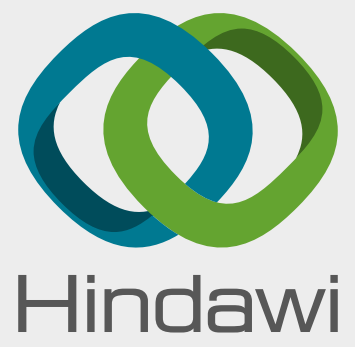

Submit your manuscripts at

www.hindawi.com
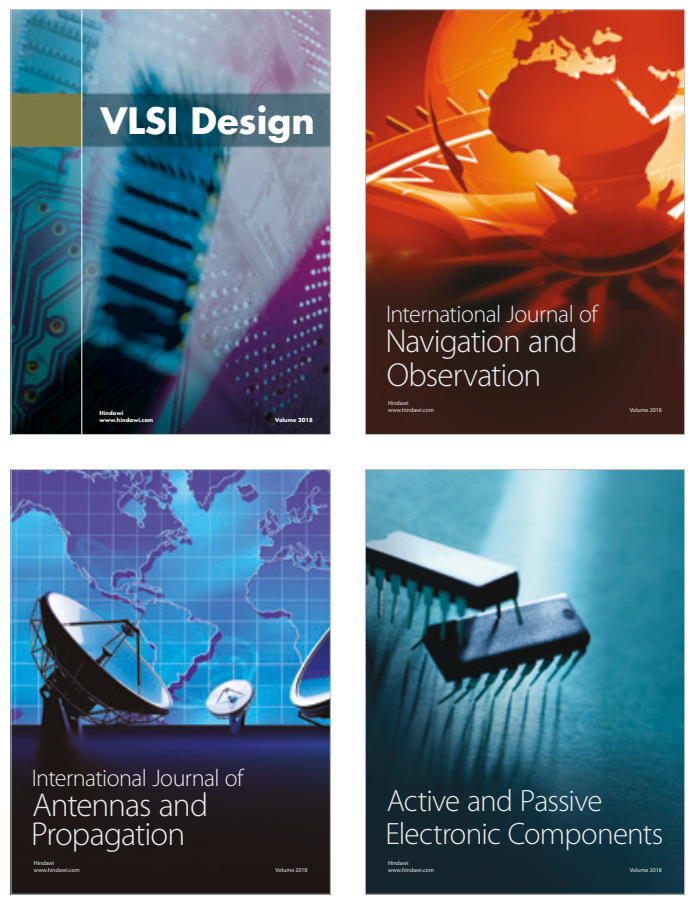
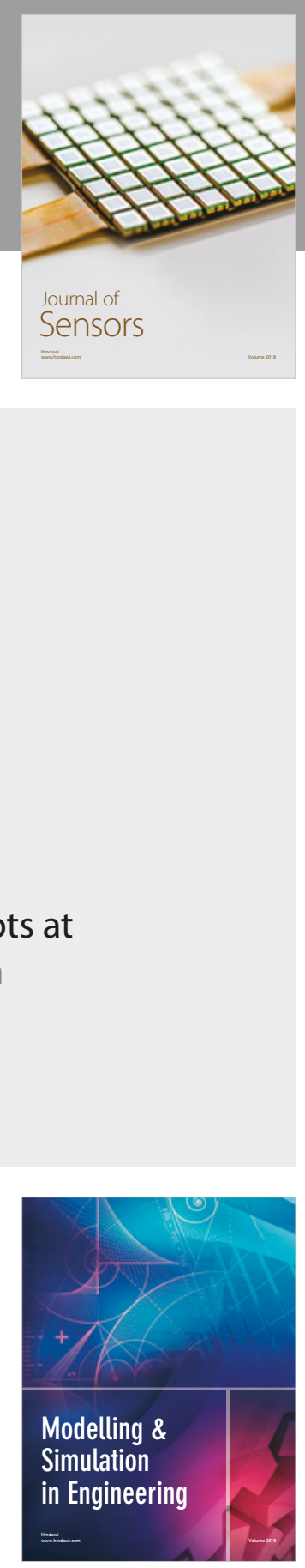

\section{Advances \\ Multimedia}
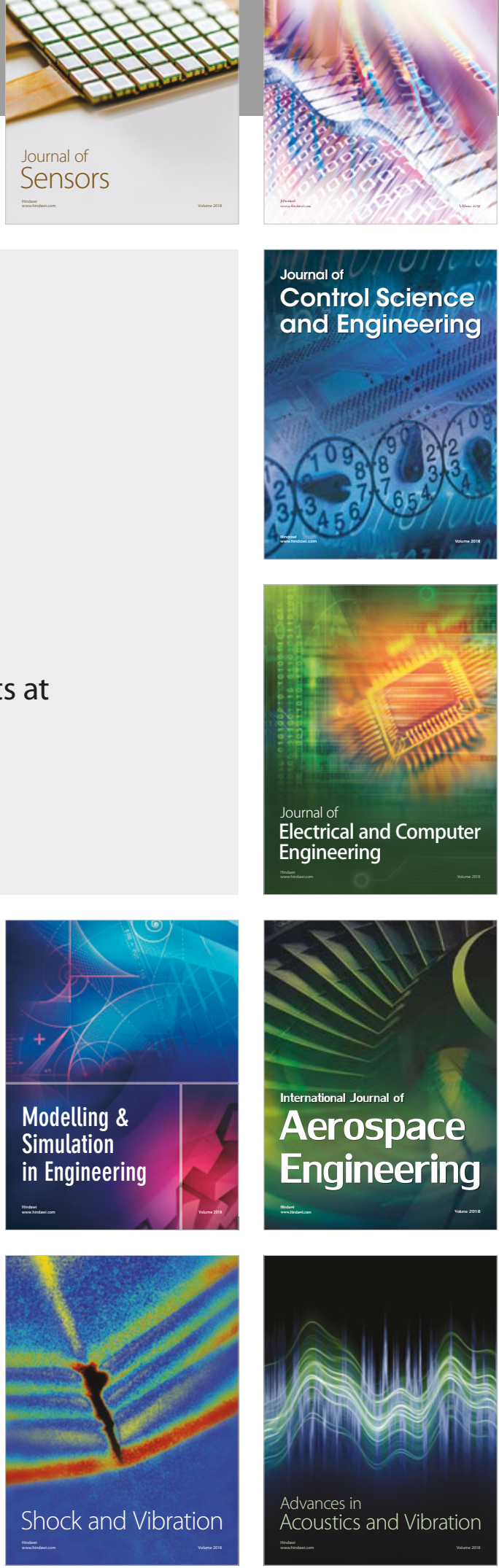